\title{
Inborn Errors of Bile Acid Metabolism
}

\author{
James E. Heubi, M.D., ${ }^{1}$ Kenneth D.R. Setchell, Ph.D., ${ }^{1}$ and Kevin E. Bove, M.D. ${ }^{1}$
}

Bile acids are synthesized by the liver from cholesterol through a complex series of reactions involving at least 14 enzymatic steps. A failure to perform any of these reactions will block bile acid production with failure to produce "normal bile acids" and, instead, result in the accumulation of unusual bile acids and intermediary metabolites. Failure to synthesize bile acids leads to reduced bile flow and decreased intraluminal solubilization of fat and fat-soluble vitamins. In some circumstances, the intermediates created because of blockade in the bile acid biosynthetic pathway may be toxic to hepatocytes. Nine recognized inborn errors of bile acid metabolism have been identified that lead to enzyme deficiencies and impaired bile acid synthesis in infants, children, and adults. Patients may present with neonatal cholestasis, neurologic disease, or fat and fat-soluble vitamin malabsorption. If untreated, progressive liver disease may develop or reduced intestinal bile acid concentrations may lead to serious morbidity or mortality. This review focuses on a description of the disorders of bile acid synthesis that are directly related to single defects in the metabolic pathway, their proposed pathogenesis, treatment, and prognosis.

KEYWORDS: Cholestasis, bile acid, cholic acid, liver

Bile acids have been implicated in the pathogenesis of liver disease; however, their exact role in initiating or perpetuating liver injury has proved difficult to discern because nonspecific alterations in serum, urinary, and biliary bile acid composition are found in infants and children with cholestasis. Specific inherited inborn errors in bile acid biosynthesis have been recently recognized that are causal in the pathogenesis of the idiopathic and familial forms of neonatal hepatitis. ${ }^{1-13}$ The deficiency in activity of specific enzymes involved in bile acid synthesis results in diminished production of the primary bile acids that are essential for promoting bile flow and the concomitant production of atypical bile acids with the potential for causing liver injury. ${ }^{14,15}$ This review outlines the pathways for bile acid synthesis and describes the clinical and biochemical characteristics of inborn errors in bile acid synthesis.

\section{CHEMISTRY AND PHYSIOLOGY}

The bile acids are a group of compounds that belong to the steroid class and are classified as acidic sterols. ${ }^{16}$ In humans, the principal bile acids synthesized by the liver $^{3,17}$ have hydroxyl groups substituted in the nucleus at the carbon positions C-3, C-7, and C-12. During early development, alternative pathways for bile acid synthesis and metabolism become quantitatively important, as is evident from the findings of relatively high proportions of bile acids hydroxylated at the $\mathrm{C}-1, \mathrm{C}-2$, C-4, and C-6 positions of the nucleus. ${ }^{18,19}$ The two principal bile acids synthesized by the liver and referred to as the "primary" bile acids are cholic acid $(3 \alpha, 7 \alpha, 12 \alpha-$ trihydroxy-5 $\beta$-cholanoic acid) and chenodeoxycholic acid ( $3 \alpha, 7 \alpha$-dihydroxy- $5 \beta$-cholanoic acid). These bile acids are extensively conjugated to the amino acids

45229-3039.

Pediatric Liver Disease: Translating Discoveries into Practice; Guest Editor, Ronald J. Sokol, M.D.

Semin Liver Dis 2007;27:282-294. Copyright (C) 2007 by Thieme Medical Publishers, Inc., 333 Seventh Avenue, New York, NY 10001, USA. Tel: +1(212) 584-4662.

DOI 10.1055/s-2007-985073. ISSN 0272-8087.
Division of Pediatric Gastroenterology, Hepatology, and Nutrition, Center, University of Cincinnati College of Medicine, Cincinnati, Ohio.

Address for correspondence and reprint requests: James E. Heubi, M.D., General Clinical Research Center, Cincinnati Children's Hospital Medical Center, 3333 Burnet Avenue, Cincinnati, OH 


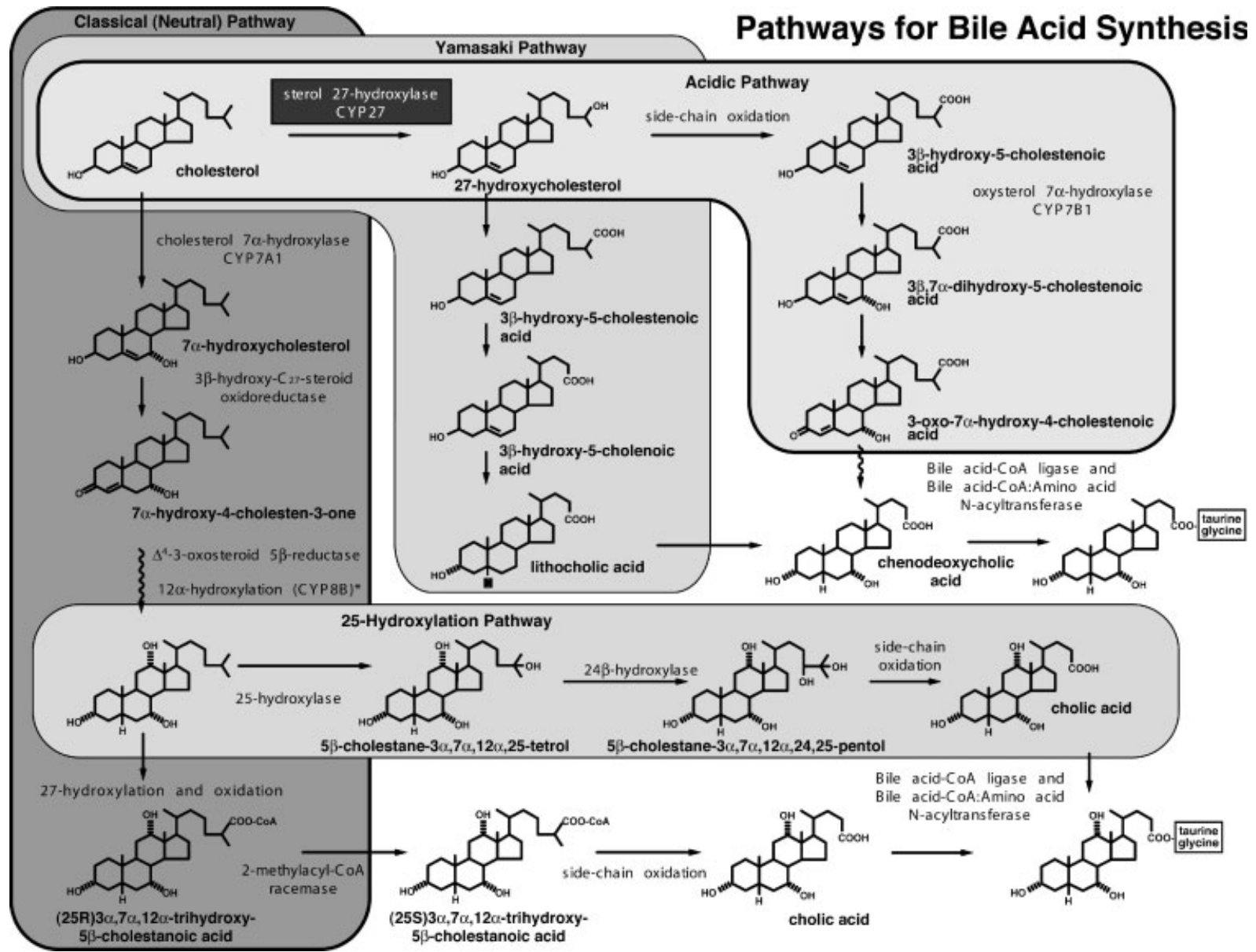

Figure 1 Metabolic pathway for the biosynthesis of the primary bile acids in the classic or "neutral" pathway and the alternative or acidic pathway. Recognized inborn errors are shown in boxes in the pathways. (Reproduced from Bove et al, ${ }^{56}$ with kind permission from Springer Science and Business Media.)

glycine and taurine. ${ }^{20}$ The biosynthetic pathway for bile acids is depicted in Fig. 1.

Bile acids perform several important functions. Bile acids are the major catabolic pathways for the elimination of cholesterol from the body. ${ }^{3,17}$ Bile acids provide the primary driving force for the promotion and secretion of bile and are essential to the development of the biliary excretory route for the elimination of endogenous and exogenous toxic substances, including bilirubin, xenobiotics, and drug metabolites. ${ }^{14}$ Within the intestinal lumen, the detergent action of bile acids facilitates the absorption of fats and fat-soluble vitamins.

Physiologically, the normal bile acid pool size in the adult is 2 to $4 \mathrm{~g}$, but the effectiveness of this pool is increased by an efficient enterohepatic recycling (10 to 12 times/day) stimulated by postprandial gallbladder contraction. ${ }^{21}$ Conservation of the bile acid pool occurs by an efficient reabsorption, principally from the small intestine, and an effective hepatic extraction from the portal venous circulation so that each day less than $5 \%$ of the pool is lost in the stool. ${ }^{22}$ This bile acid loss is compensated for by hepatic synthesis of newly formed bile acids. A fraction of the pool is converted to secondary bile acids (deoxycholic and lithocholic acid) and deconjugated with most recycled within the enterohepatic circulation and reconjugated in the liver. Although the term and preterm neonate are born with a relatively reduced, size-corrected bile acid pool, rapid expansion of the pool in the first months of life ensures adequate intraluminal concentrations for fat and fat-soluble vitamin absorption and promotion of bile flow. ${ }^{23-26}$

\section{INBORN ERRORS IN BILE ACID SYNTHESIS}

Disorders in bile acid synthesis and metabolism can be broadly classified as primary or secondary. Primary enzyme defects involve congenital deficiencies in enzymes responsible for catalyzing key reactions in the synthesis of cholic and chenodeoxycholic acids. The primary defects include cholesterol $7 \alpha$-hydroxylase (CYP7A1) deficiency; $3 \beta$-hydroxy- $\mathrm{C}_{27}$-steroid oxidoreductase deficiency; $\Delta^{4}$-3-oxosteroid $5 \beta$-reductase deficiency $^{7}$; oxysterol $7 \alpha$-hydroxylase deficiency ${ }^{9} ; 27-$ hydroxylase deficiency, or cerebrotendinous xanthomatosis (CTX); 2-methylacyl-CoA racemase deficiency; trihydroxycholestanoic acid $\mathrm{CoA}$ oxidase deficiency; 


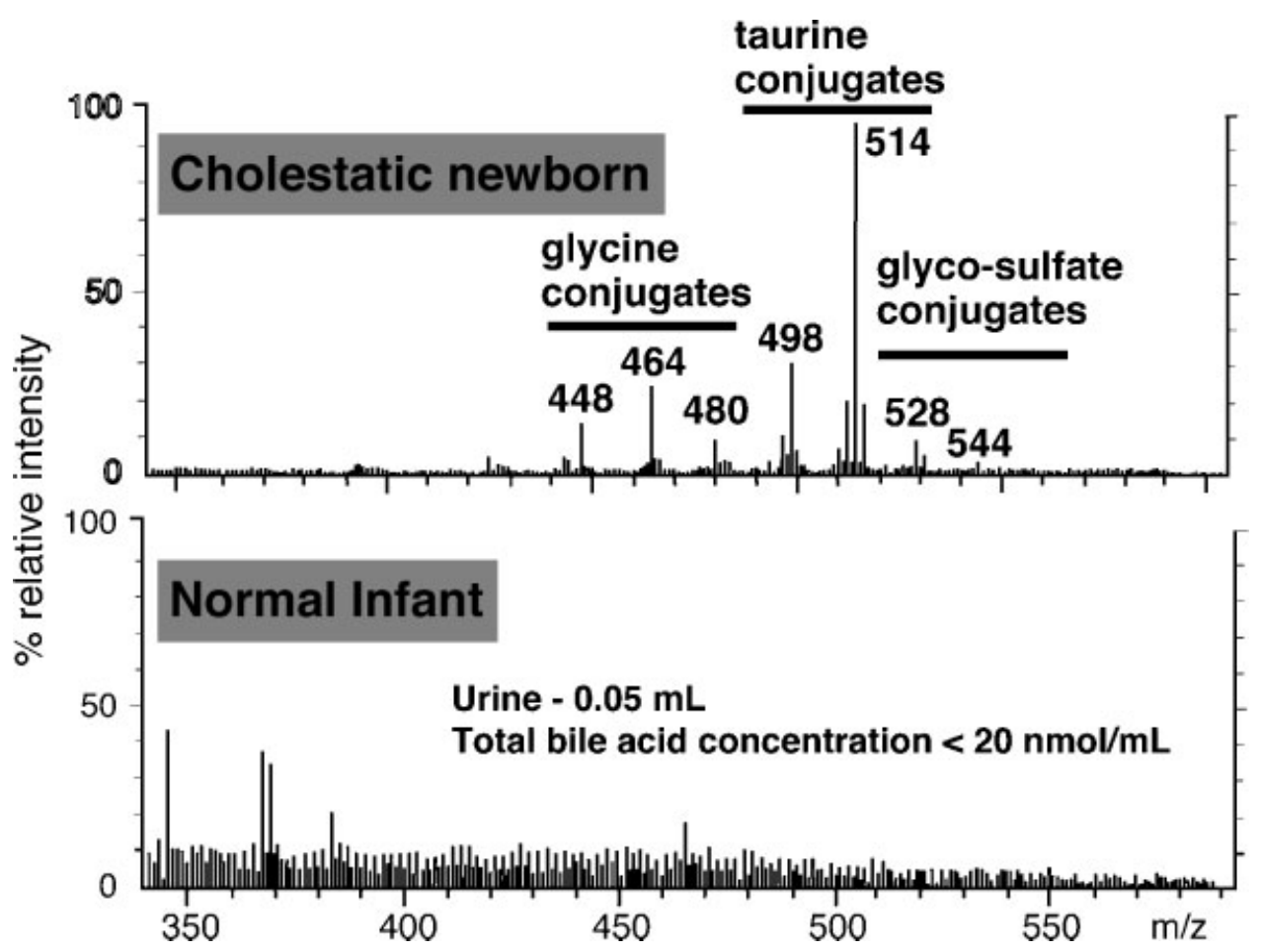

Figure 2 Negative-ion LSIMS mass spectrum analysis of typical urine from cholestatic and normal infants.

amidation defects involving a deficiency in the bile acid-CoA ligase; and side-chain oxidation defect in the 25-hydroxylation pathway for bile acid resulting in an overproduction of bile alcohols. ${ }^{27}$ Secondary metabolic defects that impact primary bile acid synthesis include peroxisomal disorders such as cerebrohepatorenal syndrome of Zellweger ${ }^{28}$ and related disorders ${ }^{29}$ and Smith-Lemli-Opitz syndrome ${ }^{30}$ caused by a deficiency of $\Delta 7$-desaturase. Secondary defects will not be discussed in this review, and excellent reviews may be found elsewhere. $^{31}$

The biochemical presentation of these bile acid synthetic defects includes a markedly reduced or complete lack of cholic and chenodeoxycholic acids in the serum, bile, and urine and greatly elevated concentrations of atypical bile acids and sterols that retain the characteristic structure of the substrates for the deficient enzyme. These signature metabolites are generally not detected by the routine or classic methods for bile acid measurement, and mass spectrometric techniques currently provide the most appropriate means of characterizing defects in bile acid synthesis. Screening procedures using liquid secondary ionization mass spectrometry (LSIMS) indicate that inborn errors in bile acid synthesis probably account for $1 \%$ to $2 \%$ of the cases of liver disease in infants, children, and adolescents, making this an important and specific category of metabolic liver disease. Typical LCIMS scans for normal and cholestatic infants are shown in Fig. 2. Over a period of 20 years, 128 bile acid synthetic defects have been identified from 7000 samples analyzed in the Mass
Spectrometry Laboratory at Children's Hospital Medical Center (Table 1). An excellent concise review for lay people and professionals is available at http://rarediseasesnetwork.epi.usf.edu/clic.

\section{CEREBROTENDINOUS XANTHOMATOSIS}

CTX is a rare inherited lipid storage disease with an estimated prevalence of 1 in $70,0000^{4,32}$ Characteristic features of the disease in adults include progressive neurologic dysfunction, dementia, ataxia, cataracts, and xanthomata in the brain and tendons and in infants with neonatal cholestasis (K.D.R. Setchell, unpublished data, 2003). Biochemically, the disease can be distinguished from other conditions involving xanthomata by (1)

Table 1 Inborn Errors of Bile Acid Metabolism $(n=128)$ Identified at Cincinnati Children's Hospital Medical Center

\begin{tabular}{ll}
\hline Diagnosis & Number \\
\hline $3 \beta$-Hydroxy- $C_{27}$-Steroid & 38 \\
$\quad$ oxidoreductase deficiency & \\
$\Delta^{4}$-3-Oxosteroid 5 $\beta$-reductase deficiency & 19 \\
27-Hydroxylase deficiency & 13 \\
Amidation defects & 11 \\
2-Methylacyl CoA racemase deficiency & 2 \\
Oxysterol 7 $\alpha$-hydroxylase deficiency & 1 \\
Peroxisomal defects (Zellweger or & 10 \\
$\quad$ neonatal leukodystrophy) & \\
Peroxisomal defects (single-enzyme defects) & 34 \\
\hline
\end{tabular}


significantly reduced primary bile acid synthesis; (2) elevations in biliary, urinary, and fecal excretion of bile alcohol glucuronides; (3) low plasma cholesterol concentration, with deposition of cholesterol and cholestanol in the tissues; and (4) marked elevations in cholestanol. Point mutations in the gene located on the long arm of chromosome 2 have been identified that lead to inactivation of the sterol 27 -hydroxylase. ${ }^{33}$

Impaired oxidation of the cholesterol side chain results in accelerated cholesterol synthesis and metabolism that leads to greatly increased production and excretion of bile alcohol glucuronides detectably by LCIMS. $^{2,34}$ The elevation in $5 \alpha$-cholestan- $3 \beta$-ol (cholestanol) in the nervous system of CTX patients and the high plasma concentrations of this sterol are unique features of the disease. ${ }^{35,36}$ Early diagnosis of this disorder, which is readily achieved by mass spectrometry analysis of the urine, is crucial to prevent the progressive accumulation of cholestanol and cholesterol in tissues in the long term. Recently, we have found several infants that had deficiencies in the sterol 27-hydroxylase owing to mutations in the gene encoding this enzyme but only because of a clinical presentation of elevated serum alanine aminotransferase (ALT) and aspartate aminotransferase (AST) and conjugated bilirubin with normal serum $\gamma$-glutamyl transpeptidase, which ultimately resolved by $\sim 6$ months of age presumably because the size of the cholic acid pool expanded with compensatory synthesis via the alternative 25 -hydroxylation pathway. The histopathology findings on liver biopsy in these young patients are similar to those observed in idiopathic neonatal hepatitis. Neonatal cholestasis may be the typical early clinical presentation of CTX even though this has never been previously documented.

\section{$3 \beta$-HYDROXY-C 27 -STEROID OXIDOREDUCTASE DEFICIENCY}

This was the first metabolic defect to be described involving an early step in the bile acid biosynthetic pathway; the conversion of $7 \alpha$-hydroxycholesterol is to $7 \alpha$-hydroxy-4-cholesten-3-one, a reaction catalyzed by a $3 \beta$-hydroxy- $\mathrm{C}_{27}$-steroid oxidoreductase. This is the most common of all of the bile acid synthetic defects described to date. Although the clinical presentation of this disorder is somewhat heterogeneous, most patients present as neonates with elevated serum ALT and AST, a conjugated hyperbilirubinemia, and normal serum $\gamma$-glutamyl transpeptidase. ${ }^{6,37-39}$ Clinical features include hepatomegaly with or without splenomegaly, fatsoluble vitamin malabsorption, and mild steatorrhea, and in most instances, pruritus is absent. The liver histology shows a generalized hepatitis, the presence of giant cells, and evidence of cholestasis ${ }^{6,37,40-42}$ (Fig. 3). The heterogeneity in clinical course of those with earlyonset disease is illustrated by some patients who initially

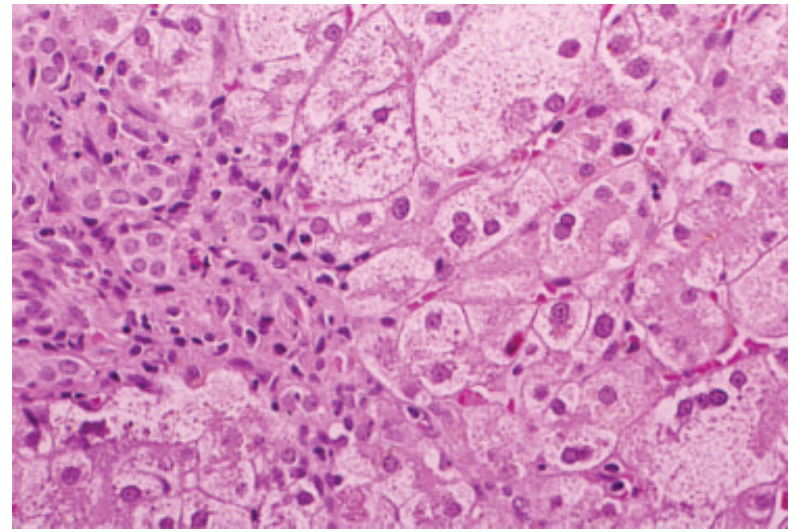

Figure 3 Liver in $3 \beta$-hydroxy- $\mathrm{C}_{27}$-steroid oxidoreductase deficiency with persistent cholestasis in a young infant. Hematoxylin and eosin-stained sections show prominent ballooned multinucleate hepatocytes. Mild portal inflammation is related to bile ductules along limiting plate (magnification, ×250).

resolve their jaundice and are identified later in life to those with more fulminant disease, eventuating in death or transplantation at an early age. Although the earliest cases were identified in infants, increasingly, idiopathic late-onset chronic cholestasis has been explained by this disorder. ${ }^{37,38}$ In such patients, liver disease is not always evident initially, and patients may have fat-soluble vitamin malabsorption and rickets, which are corrected with vitamin supplementation. Serum liver enzymes that are often normal in the early stages of the disease later show progressive increases with evidence of progressive hepatic fibrosis (Fig. 4). Definitive diagnosis of the $3 \beta-$ hydroxy- $\mathrm{C}_{27}$-steroid oxidoreductase deficiency currently requires mass spectrometric analysis of biologic fluids and is readily accomplished by LSIMS (formerly referred to as FAB-MS $)^{2,4}$ or by electrospray and tandem mass spectrometry. ${ }^{43-46}$ LSIMS analysis of the urine permits the detection of the sulfate and glycosulfate conjugates of the $3 \beta$-hydroxy- $\Delta^{5}$ bile acids that are the signature metabolites of this bile acid defect (Fig. 4).

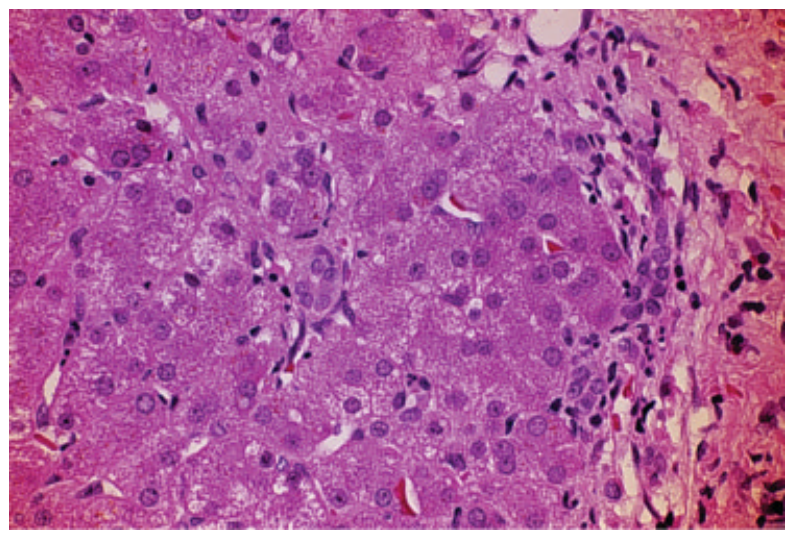

Figure 4 Liver in $3 \beta$-hydroxy- $C_{27}$-steroid oxidoreductase deficiency with mild hyperbilirubinemia presenting in later childhood. Hematoxylin and eosin-stained slide shows slight disarray of hepatocytes. Portal inflammation and periportal fibrosis is minimal (magnification, $\times 250)$. 
Molecular techniques that have led to the cloning of the HSD3B7 gene encoding $3 \beta$-hydroxy- $\mathrm{C}_{27}$-steroid oxidoreductase now permit the accurate genetic basis of the defect. ${ }^{47}$ Using this approach to confirm the biochemical diagnosis of this enzyme deficiency in 15 patients, from 13 kindreds, 12 different mutations were found to account for the disease. ${ }^{48}$ The mechanism of cholestasis and liver injury is believed to result from failure to synthesize adequate amounts of primary bile acids that are essential to the promotion and secretion of bile and the increased production of unusual bile acids with hepatotoxic potential ${ }^{15,49,50}$. Treatment with cholic acid leads to gradual resolution of biochemical and histologic abnormalities with an excellent long-term prognosis. In selected older children/adolescents presenting with extensive fibrosis or cirrhosis, cholic acid therapy has prevented progression of disease.

\section{$\Delta^{4}$-3-OXOSTEROID $5 \beta$-REDUCTASE DEFICIENCY}

Application of LSIMS for urine analysis led to the discovery of a defect in the $\Delta^{4}$-3-oxosteroid $5 \beta$-reductase, which catalyzes the conversion of the intermediates $7 \alpha$-hydroxy-4-cholesten-3-one and $7 \alpha, 12 \alpha-$ dihydroxy-4-cholesten-3-one to the corresponding 3 -oxo- $5 \beta(\mathrm{H})$ intermediates. ${ }^{7}$ The clinical presentation of this defect is similar to that of patients with the $3 \beta$-hydroxy- $\mathrm{C}_{27}$-steroid oxidoreductase deficiency; however, in contrast, the $\gamma$-glutamyl transpeptidase is usually elevated, and the average age at diagnosis is lower in patients with $\Delta^{4}$-3-oxosteroid $5 \beta$-reductase deficiency. In contrast with $3 \beta$-hydroxy-27-steroid oxidoreductase deficiency, infants with $\Delta^{4}$-3-oxosteorid $5 \beta$-reductase deficiency tend to have more severe liver disease with rapid progression to cirrhosis and death without intervention. The $\Delta^{4}$-3-oxosteroid $5 \beta$ reductase deficiency has since been found in several patients presenting with neonatal hemochromatosis. ${ }^{8}$ Liver function tests in infants with $\Delta^{4}$-3-oxosteroid $5 \beta$-reductase deficiency present with elevations in serum ALT and AST, markedly elevated serum conjugated bilirubin, and coagulopathy. Liver biopsies ${ }^{42,51}$ have revealed marked lobular disarray as a result of giant cell and pseudoacinar transformation of hepatocytes, hepatocellular and canalicular bile stasis, and extramedullary hematopoiesis (Fig. 5). On electron microscopy, bile canaliculi were small and sometimes slit-like in appearance and showed few or absent microvilli containing electron-dense material. ${ }^{7}$

Diagnosis of this defect is possible by LSIMS and gas chromatography-mass spectrometry (GC-MS) analysis of the urine. LSIMS spectra reveal elevated amounts of bile acids with molecular weights consistent with 3 -oxo-7 $\alpha$-hydroxy-4-cholenoic and 3-oxo-7 $\alpha, 12 \alpha$-dihydroxy-4-cholenoic acids, which can be confirmed with GC-MS. Gallbladder bile contains only traces (less than $2 \mu \mathrm{M}$ ) of bile acids, and urinary excretion becomes the major route for bile acid loss with $\Delta^{4}-3$ oxo bile acids comprising more than $75 \%$ of the total
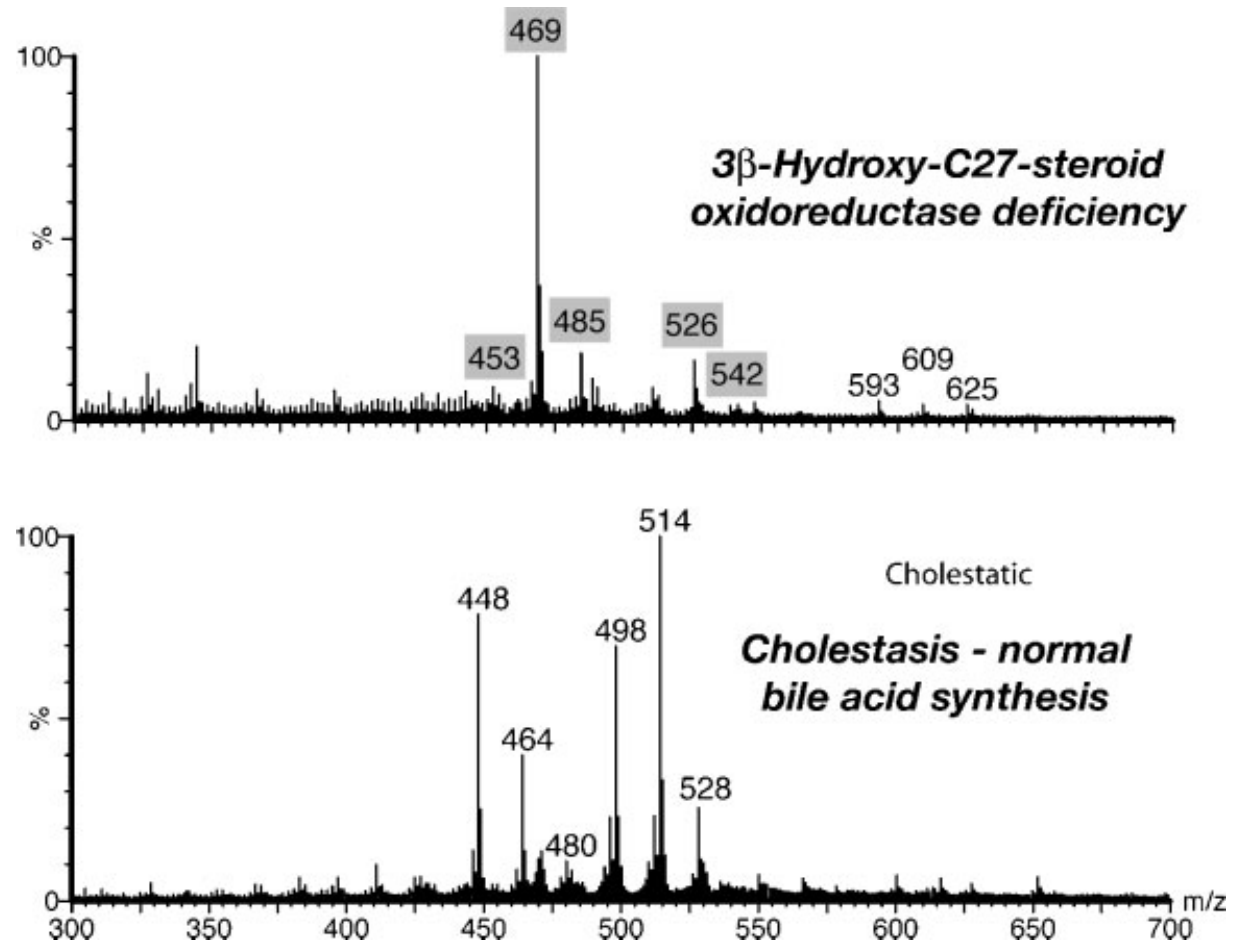

Figure 5 Negative-ion LSIMS mass spectrum analysis of typical urine from a patient with a $3 \beta$-hydroxy- $\mathrm{C}_{27}$-steroid oxidoreductase deficiency. 


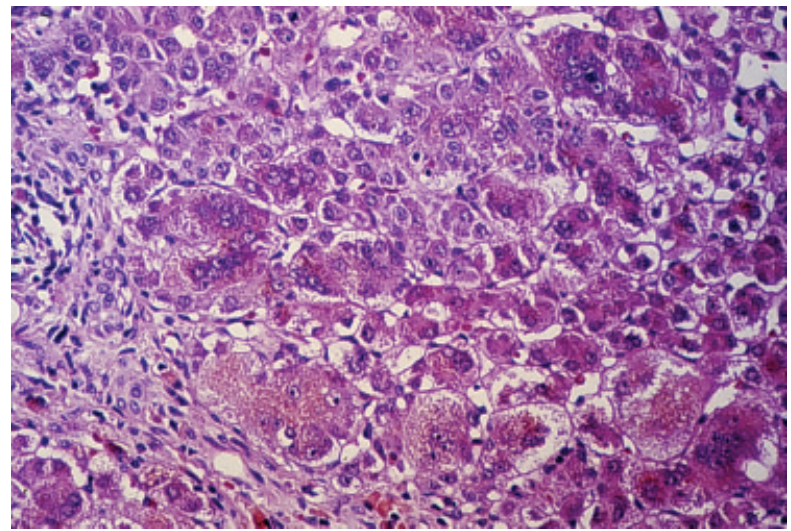

Figure 6 Liver in $\Delta^{4}$-3-oxosteroid $5 \beta$-reductase deficiency presenting with neonatal liver failure. Hematoxylin and eosinstained sections show focally prominent cytoplasmic cholestasis and giant cell transformation with minimal portal inflammation. Bile ductules are normal (magnification, $\times 250$ )

urinary bile acids. In serum, relatively high concentrations of allo-chenodeoxycholic and allo-cholic acids are found, which lends support for an active hepatic $\Delta^{4}-3$ oxosteroid $5 \beta$-reductase catalyzing the conversion of the $\Delta^{4}$-3-oxo sterol intermediates to the corresponding $3 \alpha$-hydroxy $-5 \alpha(\mathrm{H})$ structures.

The $\Delta^{4}$-3-oxosteroid $5 \beta$-reductase is exclusively of hepatic origin and, unlike $3 \alpha$-hydroxy- $\mathrm{C}_{27}$-steroid oxidoreductase, is not expressed in fibroblasts. Monoclonal antibodies raised against the rat cytosolic $\Delta^{4}-3$ oxosteroid $5 \beta$-reductase have been used to demonstrate an absence of the $38-\mathrm{kDa}$ protein in several of these patients and the formation of a truncated protein. ${ }^{3}$ In 1 patient from Japan who met our previous biochemical criteria for a deficiency in this enzyme, sequence analysis of the gene revealed a single silent mutation in the coding region of the gene, ${ }^{52}$ but the protein was normally expressed when analyzed by immunoblot of the liver homogenate using a monoclonal antibody. ${ }^{53}$

Increased production of $\Delta^{4}$-3-oxo bile acids occurs in patients with severe liver disease $\mathrm{e}^{54}$ and in infants during the first few weeks of life. ${ }^{55}$ It is important to perform a repeat analysis of urine in the case of a suspected $\Delta^{4}$-3-oxosteroid $5 \beta$-reductase deficiency because on rare occasions, a resolution of the liver disease occurs and the atypical bile acids disappear. ${ }^{56}$

The liver injury in this defect is presumed to be the consequence of the diminished primary bile acid synthesis and the hepatotoxicity of the accumulated $\Delta^{4}$ 3 -oxo bile acids (Fig. 6). The lack of canalicular secretion can be explained by the relative insolubility of oxo-bile acids, and the cholestatic effects of the taurine conjugate of $7 \alpha$-dihydroxy-3-oxo-4-cholenoic acid have been demonstrated in rat canalicular plasma membrane vesicles. ${ }^{15}$ The unique morphologic findings in these patients ${ }^{51}$ may indicate that maturation of the canalicular membrane and the transport system for bile acid secretion may require a threshold concentration of primary bile acids in early development. Treatment with ursodeoxycholic acid or cholic acid leads to resolution of histologic and biochemical abnormalities with an excellent long-term prognosis.

\section{OXYSTEROL $7 \alpha$-HYDROXYLASE DEFICIENCY}

The recent discovery of a genetic defect in oxysterol $7 \alpha-$ hydroxylase ${ }^{9}$ establishes the acidic pathway as a quantitatively important pathway for bile acid synthesis in early life. In the human, the oxysterol $7 \alpha$-hydroxylase may be more important than cholesterol $7 \alpha$-hydroxylase for bile acid synthesis in early life. This defect has been found in only 1 infant, a 10-week-old boy of parents who were first cousins, who presented with severe progressive cholestasis, hepatosplenomegaly, cirrhosis, and liver synthetic failure from early infancy. Serum ALT and AST were markedly elevated, and serum $\gamma$-glutamyl transpeptidase was normal. Liver biopsy findings included cholestasis, bridging fibrosis, extensive giant cell transformation, and proliferating bile ductules. ${ }^{9}$ Oral UDCA therapy led to deterioration in liver function tests, and oral cholic acid was therapeutically ineffective. The patient subsequently underwent orthotopic liver transplant at $4 \frac{1}{2}$ months of age but died from disseminated Epstein-Barr virus-related lymphoproliferative disease.

Analysis of the urine by LSIMS revealed intense ions in the spectrum at mass-to-charge ratio $(\mathrm{m} / \mathrm{z}) 453$ and $\mathrm{m} / \mathrm{z} 510$, corresponding with sulfate and glycosulfate conjugates of $3 \beta$-hydroxy-5-cholenoic and $3 \beta$-hydroxy-5-cholestenoic acids. These accounted for $97 \%$ and $86 \%$ of the total serum and urinary bile acids, respectively, and primary bile acids were virtually undetectable. Monohydroxy bile acids with the $3 \beta-$ hydroxy $-\Delta^{5}$ structure have been previously shown to be extremely cholestatic. ${ }^{49,57}$ Their hepatotoxicity in this patient is presumed to have been exacerbated by the lack of primary bile acids necessary for the maintenance of bile flow.

Oxysterol $7 \alpha$-hydroxylase mRNA was also not present in this patient's liver tissue, and analysis of the oxysterol $7 \alpha$-hydroxylase gene revealed a cytosine-tothymidine transition mutation in exon 5 that converts an arginine codon at position 388 to a stop codon. The patient was homozygous for this nonsense mutation, whereas both parents were heterozygous. ${ }^{9}$ When human embryonic 293 or Chinese hamster ovary cells were transfected with the complementary DNA (cDNA) with the R388* mutation, there was no detectable $7 \alpha$ hydroxylase activity, and immunoblot analysis confirmed that the mutated gene encoded a truncated and inactive protein.

Unlike the other two nuclear defects in bile acid synthesis, the oxysterol $7 \alpha$-hydroxylase deficiency is particularly severe and untreatable by primary bile acid 
therapy. The characteristic metabolites formed in the genetic defect are some of the most cholestatic bile acids known, and, clearly, oxysterol $7 \alpha$-hydroxylase is crucial for protecting the liver against the toxicity of monohydroxy bile acids produced in the acidic pathway.

\section{2-METHYLACYL-CoA RACEMASE DEFICIENCY}

2-Methylacyl-CoA racemase is a crucial enzyme that is uniquely responsible for the racemization of $(25 R)$ THCA-CoA to its $(25 S)$ enantiomer and also performs the same reaction on the branched-chain fatty acid $(2 R)$ pristanoyl-CoA. Defects in this enzyme therefore have profound effects on both the bile acid and the fatty acid pathways. Mutations in the gene encoding 2methylacyl-CoA racemase were first reported in 3 adults who presented with a sensory motor neuropathy ${ }^{58}$ and later in a 10-week-old infant who had severe fat-soluble vitamin deficiencies, hematochezia, and mild cholestatic liver disease. ${ }^{13}$ Liver histologic findings included cholestasis and giant cell transformation with modest inflammation. The infant had the same missense mutation (S52P) as that described in 2 of the adult patients yet was seemingly phenotypically quite different. ${ }^{13}$ Two of the adult patients had neurologic symptoms but were asymptomatic until the fourth decade of life, whereas the other adult was described as having the typical features of Niemann-Pick type $\mathrm{C}$ disease at 18 months of age and presumably had some liver dysfunction. The clinical descriptions of these adult patients, in particular the early history, were too scant to draw conclusions about the phenotypic differences between the adult and the early presentation of the 2-methylacyl-CoA racemase. It is therefore possible that these adults could have had undocumented mild liver disease and fat-soluble vitamin absorption early in life that, if undiagnosed in infancy, would probably lead to a neuropathy owing to the tissue accumulation of phytanic and pristanic acids. In the first infant described with the 2-methylacyl-CoA racemase deficiency, the liver from a 51/2-month-old sibling, who 2 years previously had died from an intracranial bleed, had been transplanted into a child with end-stage liver disease. ${ }^{13}$ Analysis of the urine from the recipient confirmed the same biosynthetic defect in the donor liver. Diagnosis of the defect in the infant was based on urinary, serum, and biliary bile acid analysis by FAB-MS, GC-MS, and electrospray ionization-tandem mass spectrometry, which revealed subnormal levels of primary bile acids and markedly increased concentrations of cholestanoic (C27) acids, which are characteristically found as major bile acids of the alligator, other reptiles, and amphibians. ${ }^{59,60}$ The mass spectrum and GC profiles in this defect resemble closely those observed in peroxisomal disorders affecting bile acid synthesis, such as Zellweger syndrome. Fibroblast studies can be used to further confirm a deficiency in peroxisomal 2-methylacyl-CoA racemase. ${ }^{61}$ Primary bile acid therapy with cholic acid has proved effective in normalizing liver enzymes and preventing the onset of neurologic symptoms in the infant; additionally, dietary restriction of phytanic acid and pristanic acids is likely to be necessary in the long-term for such patients to prevent neurotoxicity from accumulation of these fatty acids in the brain.

\section{THCA-COA OXIDASE DEFICIENCY}

Several patients have been reported to have side-chain oxidation defects involving the THCA-CoA oxidase. $^{12,62-65}$ The clinical presentation differs among these cases, and although all impact on primary bile acid synthesis, neurologic disease was the main clinical feature. ${ }^{12}$ Whether these are primary bile acid defects or secondary to single-enzyme defects in peroxisomal $\beta$-oxidation is unclear. Two distinct acyl-CoA oxidases have been identified in humans. ${ }^{64}$ The human acyl-CoA oxidase active on bile acid $\mathrm{C}_{27}$ cholestanoic acid intermediates has been found to be the same enzyme that catalyzes the oxidation of 2-methyl branched-chain fatty acids. ${ }^{64}$ The cDNA of the gene encoding this human enzyme has been cloned. ${ }^{66}$ Of the case reports in the literature of the proposed THCA-CoA oxidase deficiency, interestingly, phytanic and pristanic acids, when measured, were elevated. ${ }^{12,32,62-65}$ All had ataxia as a primary feature of the disease, with its onset occurring at $\sim 3^{1} \frac{1}{2}$ years of age. None had evidence of liver disease. It is possible, with the exception of the patient described by Clayton and colleagues, ${ }^{12}$ that these patients had a 2-methylacyl-CoA racemase deficiency, but the analysis of the cholestanoic acids was not sufficiently detailed to permit the diastereoisomers of THCA and $3 \alpha, 7 \alpha$-dihydroxy- $5 \beta$-cholestanoic acid (DHCA) or pristanic acid to be measured, which would have helped in the differential diagnosis. In the case of the patient reported by Clayton and colleagues, we excluded 2-methylacyl-CoA racemase deficiency as an explanation for the clinical presentation. ${ }^{12}$ The phenotypic presentation of defects involving the peroxisomal apparatus can present with a wide diversity in symptoms that make it difficult to pinpoint the exact defect involved. In all suspected cases, analysis of peroxisomal enzymes, pristanic and phytanic acids, VLCFAs, and plasmalogens should be performed to complement detailed bile acid analysis.

\section{BILE ACID COA LIGASE DEFICIENCY AND DEFECTIVE AMIDATION}

The final step in bile acid synthesis involves conjugation with the amino acids glycine and taurine. ${ }^{20}$ Hepatic conjugation is extremely efficient, and negligible amounts of unconjugated bile acids typically appear in 
bile under normal and cholestatic conditions ${ }^{67}$ and also when large doses of an unconjugated bile acid such as UDCA are administered. ${ }^{68}$ Two enzymes catalyze the reactions leading to amidation of bile acids. In the first, a CoA thioester is formed by the rate-limiting bile acidCoA ligase, after which glycine or taurine is coupled in a reaction catalyzed by a cytosolic bile acid-CoA:amino acid $N$-acyltransferase.

A defect in bile acid amidation, presumed to involve the bile acid-CoA ligase, was described in patients presenting with fat and fat-soluble vitamin malabsorption. ${ }^{11}$ The index case was a 14 -year-old boy of Laotian descent who, in the first 3 months of life, presented with conjugated hyperbilirubinemia, elevated serum transaminases, and normal $\gamma$-glutamyl transpeptidase. This child also had a form of $\beta$-thalassemia. Subsequently, additional patients have been identified who have presented with a history of neonatal cholestasis, growth failure, or fat-soluble vitamin deficiency.

The diagnosis is based on the LSIMS analysis of the urine and serum and bile, which reveals unique negative-ion spectra featuring a major peak of mass $(\mathrm{m} / \mathrm{z}$ 407) corresponding with unconjugated cholic acid. In addition, ions characterizing sulfate and glucuronide conjugates of dihydroxy and trihydroxy bile acids were present. There was a complete lack of the usual glycine and taurine conjugated bile acids, and this was confirmed after chromatographic separation and GCMS. Serum and urinary bile acids were markedly elevated and comprised predominately cholic and deoxycholic acids. The initial patients identified have been lost to follow-up, making it impossible to ascertain the molecular genetics of the defect despite the fact that the cDNAs for both conjugating enzymes have been cloned. ${ }^{69,70}$ All recently identified patients with this defect have all been identified with mutations in the bile acid-CoA ligase gene.

Carlton et al have described kindred of Amish descent with mutations in the bile acid-CoA:amino acid $N$-acyltransferase (BAAT). ${ }^{71}$ Patients homozygous for the 226G mutation had increased serum bile acids and variable growth failure and coagulopathy without jaundice and normal serum $\gamma$-GT concentrations. Homozygotes had only unconjugated bile acids in serum, and heterozygotes had increased amounts of unconjugated serum bile acids.

Administration of conjugates of the primary bile acid, glycocholic acid, to 2 recently identified patients has improved their growth and should correct the fatsoluble vitamin malabsorption in this defect. The recognition that genetic defects in bile acid synthesis are associated with fat-soluble vitamin malabsorption warrants a more concerted effort to explore this type of patient population, particularly as conjugated bile acids in the form of glycocholic acid are available under a treatment Investigational New Drug application (IND).

\section{SIDE-CHAIN OXIDATION DEFECT IN THE ALTERNATE 25-HYDROXYLATION PATHWAY}

A speculative diagnosis of a defect in side-chain oxidation in the 25-hydroxylation pathway ${ }^{72-74}$ was proposed by Clayton and colleagues for a 9-week-old infant presenting with familial giant cell hepatitis and severe intrahepatic cholestasis. ${ }^{27}$ The rationale for the diagnosis was based on the finding of reduced cholic and chenodeoxycholic acids in the serum, concomitant with high concentrations of bile alcohol glucuronides. These bile alcohols are not normally found in the plasma of infants with liver disease. Bile alcohol glucuronides were also identified as major metabolites in the urine. ${ }^{27}$ Although the profile resembled that seen in CTX patients, it was concluded on the basis of the liver disease (not previously reported for CTX) that this represented a different sidechain defect and that it was possibly an oxidation defect downstream of the 25-hydroxylation step in this minor pathway for bile acid synthesis. The implications of the findings are that it could indicate that the 25-hydroxylation pathway, considered of negligible importance in adults, ${ }^{74}$ may be an important pathway for infants. This is speculation, and further studies to prove the exact site of the defect are required before this is convincing. The patient was, however, treated with chenodeoxycholic acid and cholic acid, and this led to normalization in serum transaminases and suppression in the production of bile alcohols.

\section{CHOLESTEROL $7 \alpha$-HYDROXYLASE DEFICIENCY}

Several patients have recently been identified with a homozygous mutation deletion in the CYP7A1 gene, and when the cDNA of this mutant was expressed in vitro in cultured HEK 293 cells, cholesterol 7 $\alpha$-hydroxylase was found to be inactive. ${ }^{75}$ Bile acid synthesis was reduced, and upregulation of the alternative sterol 27-hydroxylase pathway presumably compensated for the reduced synthesis of bile acids via absent cholesterol $7 \alpha$-hydroxylase activity. Three patients carrying this mutation were found to have abnormal serum lipids, but, in contrast with an infant identified with a mutation in oxysterol $7 \alpha$-hydroxylase, ${ }^{9}$ there was no liver dysfunction in these patients. Instead, the clinical phenotype was one of markedly elevated total and low-density lipoprotein (LDL) cholesterol and premature gallstones in 2 patients and premature coronary and peripheral vascular disease in 1 patient. The elevated serum cholesterol concentration was unresponsive to $\mathrm{HMG}-\mathrm{CoA}$ reductase inhibitor therapy. Interestingly, individuals 
who were shown to be heterozygous for this mutation were found to have an above-normal level of serum cholesterol. The phenotype of this deficiency in cholesterol $7 \alpha$-hydroxylase differed significantly from that expressed in the CYP7A1 knockout mouse model. ${ }^{76}$

\section{DIAGNOSIS AND TREATMENT OF INBORN ERRORS IN BILE ACID SYNTHESIS}

Accurate identification of inborn errors in metabolism requires techniques that afford detailed metabolic profiles, and for the moment, GC-MS continues to be the principal confirmatory analytical tool. ${ }^{77-79}$ Because of the high cost, technical difficulty, and time-consuming nature of bile acid analysis by GC-MS, the technique is outside the scope of most routine clinical laboratories. Perhaps the most significant advances in mass spectrometry in recent years have been the introduction of FABMS and electrospray mass spectrometry, both of which are referred to by the generic term LSIMS. These techniques greatly simplified and extended the scope of mass spectrometry so that many nonvolatile compounds can be analyzed rapidly and directly in biologic samples or simple crude extracts, thereby circumventing the need for extensive and time-consuming sample pretreatments. Intact bile acid conjugates are ideally suited to LSIMS, and negative ionization mass spectra of steroid and bile acid conjugates can be generated from microliter volumes of urine and blood. ${ }^{2,77,80-86}$

In healthy individuals, urinary bile acid excretion is of negligible quantitative importance; consequently, the mass spectrum obtained is unremarkable, showing only background ions from the matrix and the presence of some steroid hormone metabolites. During cholestasis, urinary bile acid excretion increases and bile acid conjugates can be readily detected by the presence of single intense ions corresponding with the pseudomolecular $\left([\mathrm{M}-\mathrm{H}]^{-}\right)$ions (Fig. 2).

With cholestasis, and in the absence of an inborn error in bile acid synthesis, the ions corresponding with the glyco- and tauroconjugates of the primary bile acids appear in the mass spectrum, and the intensity of the ions is proportional to the degree of cholestasis. ${ }^{2}$ When bile acid synthesis is impaired, a unique mass spectrum is obtained, revealing ions corresponding in mass to the accumulated intermediates and/or metabolites with structural characteristics of the substrates proximal to the enzyme block. Positive identification of these bile acids generally requires GC-MS analysis after prior hydrolysis of the conjugates and preparation of volatile derivatives, and this is a time-consuming technique. The potential for rapid screening of bile acid defects has been realized with the electrospray ionization-mass spectrometry, and bile acid metabolites can be detected in dried blood spots obtained from newborns for the Guthrie test. ${ }^{45}$ This approach allows fast throughput of samples for screening, but definitive diagnosis of suspected inborn errors in bile acid synthesis is still likely to be complemented with GC-MS and, for the moment, will be restricted to specialist laboratories. Now that many of the genes encoding the enzymes involved in bile acid synthesis have been cloned, the application of molecular techniques to sequence DNA from patients identified by mass spectrometry as having bile acid synthetic defects is an important complementary tool and should prove of value in prenatal diagnosis in these familial diseases.

Although it is clear that FAB-MS screening may be the best means to identify inborn errors of bile acid metabolism, the turnaround time for the assay is sometimes slow. As a screening test, in assessing infants with conjugated hyperbilirubinemia, it may be practical to measure serum bile acids by a standard laboratory technique that will identify primary and secondary bile acids but not the metabolites typically seen in the inborn errors of bile acid metabolism. If the serum bile acids by this technique are elevated, one can safely assume one has ruled out the more life-threatening defects such as $3 \beta$ hydroxy- $\mathrm{C}_{27}$ steroid oxidoreductase deficiency, $\Delta^{4}$-oxo$5 \beta$ reductase deficiency, and oxysterol $7 \alpha$-hydroxylase deficiency. This simple screen would not necessarily rule out defects of amidation, which typically present with fat and fat-soluble vitamin malabsorption, or 27-hydroxylase deficiency, and FAB-MS would be essential for screening. It is also essential to note that if ursodeoxycholic acid is being administered during the screening with either the urine FAB-MS or conventional serum bile acid methods, the results may be difficult to interpret so all specimens should be collected after a period of $\sim 7$ to 10 days off UDCA.

Early diagnosis of inborn errors in bile acid synthesis is important because if untreated, these conditions may be fatal. The possibility of bile acid synthetic defects in older children, and even in some adults with idiopathic forms of liver disease, should also be considered given that many cases of $3 \beta$-hydroxy- $\mathrm{C}_{27}$-steroid oxidoreductase have been found in older children and teenagers presenting with late-onset chronic cholestasis.

The earliest experience with feeding a primary bile acid was for the treatment of CTX, ${ }^{87,88}$ even though this is not a condition that is manifested as liver disease. Longterm treatment with chenodeoxycholic acid ( $750 \mathrm{mg} /$ day) normalized plasma cholestanol concentrations, ${ }^{88,89}$ markedly reduced the urinary excretion of bile alcohols, ${ }^{2,88,90}$ and improved the clinical condition. ${ }^{90-92}$ Treatment of these patients may be more effective if bile acid is combined with an HMG-CoA reductase inhibitor because this combination has a greater effect in lowering plasma cholestanol. ${ }^{93,94}$

Oral bile acid therapy was found to be an effective means of treating patients with the $3 \beta$-hydroxy- $\mathrm{C}_{27^{-}}$ steroid oxidoreductase deficiency, $\Delta^{4}$-3-oxosteroid $5 \beta$ reductase deficiency, and 2-methylacyl-CoA racemase 
deficiency. ${ }^{37,95,96}$ Cholic acid, available under a treatment IND, is the therapy of choice and has been shown to be effective in a dose range of 10 to $15 \mathrm{mg} / \mathrm{kg}$ body weight/day. UDCA has proved helpful for some patients with the $3 \beta$-hydroxy- $\mathrm{C}_{27}$-steroid oxido reductase deficiency, lowering serum transaminases and improving liver histology. ${ }^{38}$ However, it does not suppress the synthesis of atypical $3 \beta$-hydroxy $-\Delta^{5}$ bile acids, which over the long-term is important given that these bile acids are cholestatic and interfere with canalicular bile acid transport. ${ }^{15,51}$ When UDCA was used in combination with cholic acid, it was our experience that the effectiveness of cholic acid in downregulating endogenous bile acid synthesis was reduced, and this we believe is because UDCA during its enterohepatic recycling competitively inhibits the ileal uptake of cholic acid.

The success of this therapeutic approach for patients with these 3 defects, ${ }^{37,38,95,96}$ is evident from the few treatment failures, and several patients have avoided the need for orthotopic liver transplant even though they were wait-listed for a donor liver. One notable failure was the treatment of the only patient found to have a mutation in the oxysterol $7 \alpha$-hydroxylase gene. ${ }^{9}$ Cholic acid therapy was unable to downregulate the synthesis of the oxysterols and hepatotoxic $3 \beta$-hydroxy $-\Delta^{5}$-monohydroxy bile acids, and this patient eventually underwent transplant. ${ }^{9}$

Finally, what can be offered to patients with a bile acid conjugation (amidation) defect ${ }^{11}$ ? In these cases, they are able to make unconjugated bile acids, mostly cholic acid, yet they fail to absorb fat-soluble vitamins. Restoring the conjugated bile acid pool seems logical, and this is possible by administration of a conjugated bile acid such as taurocholate or glycocholate. Alternatively, cholylsarcosine may also be helpful because this has been shown to improve fat absorption in a patient with shortbowel syndrome. ${ }^{97}$ Recent experience with glycocholic acid suggests that it is an effective therapy for this condition; however it is only available under a treatment IND. ${ }^{98}$

\section{CONCLUSION}

Inborn errors in bile acid synthesis represent a specific category of metabolic liver disease. These disorders have a significant effect on gastrointestinal physiology and function because of the key role that bile acids play in maintaining the enterohepatic circulation and in facilitating the absorption of fat and fat-soluble vitamins. At the Cincinnati Children's Hospital Medical Center, more than 130 patients have been identified with defects, accounting for $1 \%$ to $2 \%$ of the cases of unexplained liver disease in infants and children. Early diagnosis is important because the liver disease and fat-soluble vitamin malabsorption associated with these inborn errors can be successfully treated medically, thereby avoiding ortho- topic liver transplant in what may otherwise be progressive and fatal conditions when undiagnosed or untreated.

\section{ACKNOWLEDGMENTS}

Supported in part by National Institutes of Health grant M01-RR-08084, General Clinical Research Center, National Center for Research Resources, and grant U54 RR019455, Rare Liver Disease Network, National Center for Research Resources.

\section{ABBREVIATIONS}

\begin{tabular}{|c|c|}
\hline BAAT & $\begin{array}{l}\text { bile acid-CoA:amino acid } N \text {-acyltrans- } \\
\text { ferase }\end{array}$ \\
\hline cDNA & complementary DNA \\
\hline $\mathrm{CoA}$ & coenzyme A \\
\hline CTX & cerebrotendinous xanthomatosis \\
\hline CYP7A1 & cholesterol $7 \alpha$-hydroxylase \\
\hline DHCA & $3 \alpha, 7 \alpha$-dihydroxy- $5 \beta$-cholestanoic acid \\
\hline FAB-MS & $\begin{array}{l}\text { fast atom bombardment-mass spectro- } \\
\text { metry }\end{array}$ \\
\hline$\gamma-\mathrm{GT}$ & gamma-glutamyl transpeptidase \\
\hline GC-MS & gas chromatography-mass spectrometry \\
\hline HMG-CoA & hydroxymethylglutaryl-coenzyme A \\
\hline IND & Investigational New Drug application \\
\hline LSIMS & $\begin{array}{l}\text { liquid secondary ionization mass spec- } \\
\text { trometry }\end{array}$ \\
\hline LDL & low-density lipoprotein \\
\hline THCA & trihydroxycholestanoic acid \\
\hline UDCA & ursodeoxycholic acid \\
\hline VLCFAs & very long chain fatty acids \\
\hline
\end{tabular}

\section{REFERENCES}

1. Setchell KDR, Kritchevsky D, Nair PP. The Bile Acids: Methods and Applications. New York, NY: Plenum Press; 1988

2. Setchell KDR, Street JM. Inborn errors of bile acid synthesis. Semin Liver Dis 1987;7:85-99

3. Russell DW, Setchell KDR. Bile acid biosynthesis. Biochemistry 1992;31:4737-4749

4. Setchell KDR, O'Connell NC. Inborn errors of bile acid metabolism. In: Suchy FJ, ed. Liver Disease in Children. St. Louis, MO: Mosby-Yearbook Inc; 1994:835-851

5. Setchell KDR. Disorders of bile acid synthesis and metabolism. In: Walker WA, Durie PR, Hamilton JR, et al, eds. Pediatric Gastrointestinal Disease: Pathophysiology, Diagnosis, Management. Philadelphia, PA: BC Decker Inc; 1996:1205-1233

6. Clayton PT, Leonard JV, Lawson AM, et al. Familial giant cell hepatitis associated with synthesis of 3 beta, 7 alphadihydroxy-and 3 beta,7 alpha, 12 alpha-trihydroxy-5cholenoic acids. J Clin Invest 1987;79:1031-1038

7. Setchell KDR, Suchy FJ, Welsh MB, et al. Delta 4-3oxosteroid 5 beta-reductase deficiency described in identical twins with neonatal hepatitis: a new inborn error in bile acid synthesis. J Clin Invest 1988;82:2148-2157

8. Shneider BL, Setchell KDR, Whitington PF, et al. Delta 43-oxosteroid 5 beta-reductase deficiency causing neonatal 
liver failure and hemochromatosis. J Pediatr 1994;124:234238

9. Setchell KDR, Schwarz M, O'Connell NC, et al. Identification of a new inborn error in bile acid synthesis: mutation of the oxysterol 7alpha-hydroxylase gene causes severe neonatal liver disease. J Clin Invest 1998;102:16901703

10. Setchell KDR, O'Connell NC, Squires RH, Heubi JE. Congenital defects in bile acid synthesis cause a spectrum of diseases manifest as severe cholestasis, neurological disease, and fat-soluble vitamin malabsorption. In: Northfield TC, Ahmed H, Jazwari R, Zentler-Munro P, eds. Bile Acids in Hepatobiliary Disease. Dordrecht, The Netherlands: Kluwer Academic Publishers; 1999:55-63

11. Setchell KDR, Heubi JE, O'Connell NC, et al. Identification of a unique inborn error in bile acid conjugation involving a deficiency in amidation. In: Paumgartner G, Stiehl A, Gerok W, eds. Bile Acids in Hepatobiliary Diseases: Basic Research and Clinical Application. Dordrecht, The Netherlands: Kluwer Academic Publishers; 1997:43-47

12. Clayton PT, Johnson AW, Mills KA, et al. Ataxia associated with increased plasma concentrations of pristanic acid, phytanic acid and $\mathrm{C} 27$ bile acids but normal fibroblast branched-chain fatty acid oxidation. J Inherit Metab Dis 1996;19:761-768

13. Setchell KDR, Heubi JE, Bove KE, et al. Liver disease caused by failure to racemize trihydroxycholestanoic acid: gene mutation and effect of bile acid therapy. Gastroenterology 2003;124:217-232

14. Boyer JL. New concepts of mechanisms of hepatocyte bile formation. Physiol Rev 1980;60:303-326

15. Stieger B, Zhang J, O'Neill B, et al. Transport of taurine conjugates of 7alpha-hydroxy-3-oxo-4-cholenoic acid and 3beta,7alpha-dihydroxy-5-cholenoic acid in rat liver plasma membrane vesicles. In: Van Berge-Henegouwen GP, Van Hock B, De Groote J, et al, eds. Cholestatic Liver Diseases. Dordrecht, The Netherlands: Kluwer Academic Press; 1994: 82-87

16. Klyne W. The Chemistry of the Steroids. London: Methuen and Co Ltd; 1957

17. Bjorkhem I. Mechanism of bile acid biosynthesis in mammalian liver. In: Danielsson H, Sjovall J, eds. Sterols and Bile Acids. Amsterdam, The Netherlands: BV Elsevier Science Publishers; 1985:231-277

18. Lester R, St. Pyrek J, Little JM, Adcock EW. Diversity of bile acids in the fetus and newborn infant. J Pediatr Gastroenterol Nutr 1983;2:355-364

19. Setchell KDR, Dumaswala R, Colombo C, Ronchi M. Hepatic bile acid metabolism during early development revealed from the analysis of human fetal gallbladder bile. J Biol Chem 1988;263:16637-16644

20. Sjovall J. Dietary glycine and taurine conjugation in man. Proc Soc Exp Biol Med 1959;100:676-678

21. LaRusso NF, Korman MG, Hoffman NE, Hofmann AF. Dynamics of the enterohepatic circulation of bile acids: postprandial serum concentrations of conjugates of cholic acid in health, cholecystectomized patients, and patients with bile acid malabsorption. N Engl J Med 1974;291:689692

22. Setchell KDR, Street JM, Sjovall J. Fecal bile acids. In: Setchell KDR, Kritchevsky D, Nair PP, eds. The Bile Acids: Methods and Applications. New York, NY: Plenum Press; 1988:441-570
23. Watkins JB, Ingall D, Szczepanik P, et al. Bile-salt metabolism in the newborn: measurement of pool size and synthesis by stable isotope technique. N Engl J Med 1973; 288:431-434

24. Watkins JB, Szczepanik P, Gould JB, et al. Bile salt metabolism in the human premature infant: preliminary observations of pool size and synthesis rate following prenatal administration of dexamethasone and phenobarbital. Gastroenterology 1975;69:706-713

25. Heubi JE, Balistreri WF, Suchy FJ. Bile salt metabolism in the first year of life. J Lab Clin Med 1982;100:127-136

26. Watkins JB, Jarvenpaa AL, Szczepanik-Van Leeuwen $P$ et al. Feeding the low-birth weight infant: V. Effects of taurine, cholesterol, and human milk on bile acid kinetics. Gastroenterology 1983;85:793-800

27. Clayton PT, Casteels M, Mieli-Vergani G, Lawson AM Familial giant cell hepatitis with low bile acid concentrations and increased urinary excretion of specific bile alcohols: a new inborn error of bile acid synthesis? Pediatr Res 1995;37:424431

28. Bowen P, Lee CSN, Zellweger H, Lindenberg R. A familial syndrome of multiple congenital defects. Bull Johns Hopkins Hosp 1964;114:402-414

29. Lazarow PB, Moser HW. Disorders of peroxisome biogenesis. In: Scriver CR, Beaudet AL, Sly WS, eds. The Metabolic Basis of Inherited Disease. New York, NY: McGraw-Hill; 1989:1479-1509

30. Smith DW, Lemli L, Opitz JM. A newly recognized syndrome of multiple congenital anomalies. J Pediatr 1964; 64:210-217

31. Setchell KDR, O'Connell NC. Disorders of bile acid synthesis and metabolism. In: Walker WA, Durie PR, Hamilton JR, et al, eds. Pediatric Gastrointestinal Disease. Pathophysiology, Diagnosis, Management. Phildelphia, PA: BC Decker Inc; 2000:1138-1171

32. Van Bogaert L, Scherer HJ, Epstein E. Une Forme Cerebrale de la Cholesterinose Generalisee. Paris, France: Masson et Cie; 1937

33. Cali JJ, Russell DW. Characterization of human sterol 27-hydroxylase: a mitochondrial cytochrome P-450 that catalyzes multiple oxidation reaction in bile acid biosynthesis. J Biol Chem 1991;266:7774-7778

34. Egestad B, Pettersson P, Skrede S, Sjovall J. Fast atom bombardment mass spectrometry in the diagnosis of cerebrotendinous xanthomatosis. Scand J Clin Lab Invest 1985;45:443-446

35. Salen G, Shefer S, Tint GS, et al. Biosynthesis of bile acids in cerebrotendinous xanthomatosis: relationship of bile acid pool sizes and synthesis rates to hydroxylations at C-12, C25, and C-26. J Clin Invest 1985;76:744-751

36. Koopman BJ, van der Molen JC, Wolthers BG, et al. Capillary gas chromatographic determination of cholestanol/ cholesterol ratio in biological fluids: its potential usefulness for the follow-up of some liver diseases and its lack of specificity in diagnosing CTX (cerebrotendinous xanthomatosis). Clin Chim Acta 1984;137:305-315

37. Setchell KDR, Flick R, Watkins JB, Piccoli DA. Chronic hepatitis in a $10 \mathrm{yr}$ old due to an inborn error in bile acid synthesis: diagnosis and treatment with oral bile acid. Gastroenterology 1990;98:A578

38. Jacquemin E, Setchell KD, O'Connell NC, et al. A new cause of progressive intrahepatic cholestasis: 3 beta-hydroxyC27-steroid dehydrogenase/isomerase deficiency. J Pediatr 1994;125:379-384 
39. Setchell KDR. Inborn errors of bile acid synthesis: a new category of metabolic liver disease. In: Van Berge, Henegouwen GP, Van Hoek B, De Groote J., et al eds. Cholestatic Liver Diseases: New Strategies for Prevention and Treatment of Hepatobiliary and Cholestatic Liver Diseases. Dordrecht, The Netherlands: Kluwer Academic Publishers; 1994:164-167

40. Witzleben CL, Piccoli DA, Setchell K. A new category of causes of intrahepatic cholestasis. Pediatr Pathol 1992;12: 269-274

41. Horslen SP, Lawson AM, Malone M, Clayton PT. 3 betaHydroxy-delta 5-C27-steroid dehydrogenase deficiency: effect of chenodeoxycholic acid therapy on liver histology. J Inherit Metab Dis 1992;15:38-46

42. Bove KE, Daugherty CC, Tyson W, et al. Bile acid synthetic defects and liver disease. Pediatr Dev Pathol 2000; $3: 1-16$

43. Lemonde HA, Johnson AW, Clayton PT. The identification of unusual bile acid metabolites by tandem mass spectrometry: use of low-energy collision-induced dissociation to produce informative spectra. Rapid Commun Mass Spectrom 1999;13:1159-1164

44. Libert R, Hermans D, Draye JP, et al. Bile acids and conjugates identified in metabolic disorders by fast atom bombardment and tandem mass spectrometry. Clin Chem 1991;37:2102-2110

45. Mushtaq I, Logan S, Morris M, et al. Screening of newborn infants for cholestatic hepatobiliary disease with tandem mass spectrometry. BMJ 1999;319:471-477

46. Mills KA, Mushtaq I, Johnson AW, et al. A method for the quantitation of conjugated bile acids in dried blood spots using electrospray ionization-mass spectrometry. Pediatr Res 1998;43:361-368

47. Schwarz M, Wright AC, Davis DL, et al. The bile acid synthetic gene 3b-hydroxy-5-C27-steroid oxidoreductase is mutated in progressive intrahepatic cholestasis. J Clin Invest 2000;106:1175-1184

48. Cheng JB, Jacquemin E, Gerhardt M, et al. Molecular genetics of 3b-hydroxy-5-C27-steroid oxidoreductase deficiency in 16 patients with loss of bile acid synthesis and liver disease. J Clin Endocrinol Metab 2003;88:18331841

49. Javitt NB, Emerman S. Effect of sodium taurolithocholate on bile flow and bile acid exeretion. J Clin Invest 1968;47:10021014

50. Stieger B, Zhang J, O'Neill B, et al. Differential interaction of bile acids from patients with inborn errors of bile acid synthesis with hepatocellular bile acid transporters. Eur J Biochem 1997;244:39-44

51. Daugherty CC, Setchell KD, Heubi JE, Balistreri WF. Resolution of liver biopsy alterations in three siblings with bile acid treatment of an inborn error of bile acid metabolism (delta 4-3-oxosteroid 5 beta-reductase deficiency). Hepatology 1993;18:1096-1101

52. Kondo KH, Kai MH, Setoguchi Y, et al. Cloning and expression of cDNA of human delta 4-3-oxosteroid 5 betareductase and substrate specificity of the expressed enzyme. Eur J Biochem 1994;219:357-363

53. Sumazaki R, Nakamura N, Shoda J, et al. Gene analysis in delta 4-3-oxosteroid 5 beta-reductase deficiency [letter]. Lancet 1997;349:329

54. Clayton PT, Patel E, Lawson AM, et al. 3-Oxo-delta 4 bile acids in liver disease [letter]. Lancet 1988;1:1283-1284
55. Wahlen E, Egestad B, Strandvik B, Sjoovall J. Ketonic bile acids in urine of infants during the neonatal period. J Lipid Res 1989;30:1847-1857

56. Bove KE, Heubi JE, Balistreri WF, Setchell KDR. Bile acid synthetic defects and liver disease: a comprehensive review. Pediatr Dev Pathol 2004;7:315-334

57. Mathis U, Karlaganis G, Preisig R. Monohydroxy bile salt sulfates: tauro-3 beta-hydroxy-5-cholenoate-3-sulfate induces intrahepatic cholestasis in rats. Gastroenterology 1983;85: 674-681

58. Ferdinandusse S, Denis S, Clayton PT, et al. Mutations in the gene encoding peroxisomal 2-methyl-acyl racemase cause adult-onset sensory motor neuropathy. Nat Genet 2000;24: 188-191

59. Kuramoto T, Kikuchi H, Sanemori H, Hoshita T. Bile salts of anura. Chem Pharm Bull (Tokyo) 1973;21:952-959

60. Haslewood GA. Bile salt evolution. J Lipid Res 1967;8:535550

61. Van Veldhoven PP, Meyhi E, Squires J, et al. Fibroblast studies documenting a case of peroxisomal 2-methylacylCoA racemase deficiency: possible link between racemase deficiency and malabsorption and vitamin K deficiency. Eur J Clin Invest 2001;31:714-722

62. Christensen E, Van Eldere J, Brandt NJ, et al. A new peroxisomal disorder: di- and trihydroxycholestanaemia due to a presumed trihydroxycholestanoyl-CoA oxidase deficiency. J Inherit Metab Dis 1990;13:363-366

63. ten Brink HJ, Wanders RJ, Christensen E, et al. Heterogeneity in di/trihydroxycholestanoic acidaemia. Ann Clin Biochem 1994;31:195-197

64. Vanhove GF, Van Veldhoven PP, Fransen M, et al. The CoA esters of 2-methyl-branched chain fatty acids and of the bile acid intermediates di- and trihydroxycoprostanic acids are oxidized by one single peroxisomal branched chain acylCoA oxidase in human liver and kidney. J Biol Chem 1993;268:10335-10344

65. Przyrembel H, Wanders RJ, van Roermund CW, et al. Diand trihydroxycholestanoic acidaemia with hepatic failure. J Inherit Metab Dis 1990;13:367-370

66. Masui T, Staple E. The formation of bile acids from cholesterol: the conversion of 5-beta-cholestane-3-alpha,7alpha-triol-26-oic acid to cholic acid via 5-beta-cholestane3-alpha,7-alpha,12-alpha, 24-xi-tetraol-26-oic acid I by rat liver. J Biol Chem 1966;241:3889-3893

67. Matoba N, Une M, Hoshita T. Identification of unconjugated bile acids in human bile. J Lipid Res 1986;27:11541162

68. Crosignani A, Podda M, Battezzati PM, et al. Changes in bile acid composition in patients with primary biliary cirrhosis induced by ursodeoxycholic acid administration. Hepatology 1991;14:1000-1007

69. Falany CN, Xie X, Wheeler JB, et al. Molecular cloning and expression of rat liver bile acid CoA ligase. J Lipid Res 2002;43:2062-2072

70. Shonsey EM, Wheeler J, Johnson M, et al. Synthesis of bile acid coenzyme a thioesters in the amino acid conjugation of bile acids. Methods Enzymol 2005;400:360-373

71. Carlton VE, Harris BZ, Puffenberger EG, et al. Complex inheritance of familial hypercholanemia with associated mutations in TJP2 and BAAT. Nat Genet 2003;34:91-96

72. Shefer S, Cheng FW, Dayal B, et al. A 25-hydroxylation pathway of cholic acid biosynthesis in man and rat. J Clin Invest 1976;57:897-903 
73. Duane WC, Bjorkhem I, Hamilton JN, Mueller SM. Quantitative importance of the 25-hydroxylation pathway for bile acid biosynthesis in the rat. Hepatology 1988;8:613-618

74. Duane WC, Pooler PA, Hamilton JN. Bile acid synthesis in man: in vivo activity of the 25 -hydroxylation pathway. $\mathrm{J}$ Clin Invest 1988;82:82-85

75. Pullinger CR, Eng C, Salen G, et al. Human cholesterol 7ahydroxylase (CYP7A1) deficiency has a hypercholesterolemic phenotype. J Clin Invest 2002;110:109-117

76. Schwarz M, Lund EG, Setchell KDR, et al. Disruption of cholesterol 7alpha-hydroxylase gene in mice: II. Bile acid deficiency is overcome by induction of oxysterol 7alphahydroxylase. J Biol Chem 1996;271:18024-18031

77. Setchell KDR, Lawson AM. The bile acids. In: Lawson AM, eds. Clinical Biochemistry Principles, Methods, Applications. Vol. 1: Mass Spectrometry. Berlin, Germany: Walter de Gruyter: 1988:54-125

78. Lawson AM, Setchell KDR. Mass spectrometry of bile acids. In: Setchell KDR, Kritchevsky D, Nair PP, eds. The Bile Acids. Vol. 4: Methods and Applications. New York, NY: Plenum Press; 1988:167-268

79. Sjovall J, Lawson AM, Setchell KDR. Mass spectrometry of bile acids. In: Law JH, Rilling $\mathrm{HC}$, eds. Methods in Enzymology. London, United Kingdom: Academic Press; 1985:63-113

80. Lawson AM, Madigan MJ, Shortland D, Clayton PT. Rapid diagnosis of Zellweger syndrome and infantile Refsum's disease by fast atom bombardment: mass spectrometry of urine bile salts. Clin Chim Acta 1986;161:221-231

81. Roda A, Gioacchini AM, Cerre C, Baraldini M. Highperformance liquid chromatographic-electrospray mass spectrometric analysis of bile acids in biological fluids. J Chromatogr B Biomed Appl 1995;665:281-294

82. Ikegawa S, Murao N, Motoyama T, et al. Separation and detection of bile acid 3-glucuronides in human urine by liquid chromatography/electrospray ionization-mass spectrometry. Biomed Chromatogr 1996;10:313-317

83. Lawson AM, Setchell KDR. Mass spectrometry of bile acids. In: Setchell KDR, Kritchevsky D, Nair PP, eds. The Bile Acids. Vol. 4: Methods and Applications. New York, NY: Plenum Press; 1988:167-268

84. Sjovall J, Lawson AM, Setchell KDR. Mass spectrometry of bile acids. In: Law JH, Rilling $\mathrm{HC}$, eds. Methods in Enzymology. London, United Kingdom: Academic Press; 1985:63-113

85. Evans JE, Ghosh A, Evans BA, Natowicz MR. Screening techniques for the detection of inborn errors of bile acid metabolism by direct injection and micro-high performance liquid chromatography-continuous flow/fast atom bombard- ment mass spectrometry. Biol Mass Spectrom 1993;22:331337

86. Meng LJ, Griffiths WJ, Nazer H, et al. High levels of (24S)24-hydroxycholesterol 3-sulfate, 24-glucuronide in the serum and urine of children with severe cholestatic liver disease. J Lipid Res 1997;38:926-934

87. Salen G, Meriwether TW, Nicolau G. Chenodeoxycholic acid inhibits increased cholesterol and cholestanol synthesis in patients with cerebrotendinous xanthomatosis. Biochem Med 1975;14:57-74

88. Koopman BJ, Wolthers BG, van der Molen JC, Waterreus RJ. Bile acid therapies applied to patients suffering from cerebrotendinous xanthomatosis. Clin Chim Acta 1985;152: 115-122

89. Berginer VM, Salen G, Shefer S. Long-term treatment of cerebrotendinous xanthomatosis with chenodeoxycholic acid. N Engl J Med 1984;311:1649-1652

90. Wolthers BG, Volmer M, van der Molen J, et al. Diagnosis of cerebrotendinous xanthomatosis (CTX) and effect of chenodeoxycholic acid therapy by analysis of urine using capillary gas chromatography. Clin Chim Acta 1983;131:53-65

91. van Heijst AF, Wevers RA, Tangerman A, et al. Chronic diarrhoea as a dominating symptom in two children with cerebrotendinous xanthomatosis. Acta Paediatr 1996;85:932936

92. van Heijst AF, Verrips A, Wevers RA, et al. Treatment and follow-up of children with cerebrotendinous xanthomatosis. Eur J Pediatr 1998;157:313-316

93. Lewis B, Mitchell WD, Marenah CB, et al. Cerebrotendinous xanthomatosis: biochemical response to inhibition of cholesterol synthesis. BMJ 1983;287:21-22

94. Verrips A, Wevers RA, Van Engelen BG, et al. Effect of simvastatin in addition to chenodeoxycholic acid in patients with cerebrotendinous xanthomatosis. Metabolism 1999;48: 233-238

95. Ichimiya H, Egestad B, Nazer H, et al. Bile acids and bile alcohols in a child with hepatic 3 beta-hydroxy-delta 5-C27steroid dehydrogenase deficiency: effects of chenodeoxycholic acid treatment. J Lipid Res 1991;32:829-841

96. Clayton PT, Mills KA, Johnson AW, et al. Delta 4-3oxosteroid 5 beta-reductase deficiency: failure of ursodeoxycholic acid treatment and response to chenodeoxycholic acid plus cholic acid. Gut 1996;38:623-628

97. Gruy-Kapral C, Little KH, Fordtran JS, et al. Conjugated bile acid replacement therapy for short-bowel syndrome. Gastroenterology 1999;116:15-21

98. Setchell KDR, Heubi JE. Defects in bile acid biosynthesis: diagnosis and treatment. J Pediatr Gastroenterol Nutr 2006; 43:S17-S22 